This is a self-archived - parallel published version of this article in the publication archive of the University of Vaasa. It might differ from the original.

\title{
Queering the Zombie
}

Author(s): Sihvonen, Tanja

Title: Queering the Zombie

Year: $\quad 2019$

Version: Accepted manuscript

Copyright (C)2019 Routledge. This is an Accepted Manuscript of a book chapter published by Routledge/CRC Press in The Playful Undead and Video Games: Critical Analyses of Zombies and Gameplay on 6 August 2019, available online: https://doi.org/10.4324/9781315179490

\section{Please cite the original version:}

Sihvonen, T. (2019). Queering the Zombie. In: Webley, S. J. \& Zackariasson, P. (eds.) The Playful Undead and Video Games: Critical Analyses of Zombies and Gameplay. London: Routledge. 
This is the final accepted manuscript version. Please cite the official publication:

Sihvonen, Tanja (2019) Queering the Zombie. In Stephen Webley \& Peter Zackariasson (Eds.) The Playful Undead and Video Games: Routledge Advances in Game Studies. London \& New York: Routledge.

\title{
Queering the Zombie
}

\section{Tanja Sihvonen}

\begin{abstract}
This article starts with the observation that all monsters are created by humans and thus they serve specific cultural and sociopolitical purposes. The study is set to finding out, first, how the traditional figure of the zombie works as a monster in popular culture, and second, how digital games open up new possibilities for it to exist and to act. Even if the zombie has symbolic power that makes it an ideal antagonist in games, assigning individual agency to it is very unlikely. From this follows that playing (as) the zombie in games is actively discouraged. The analysis presented here differs from earlier research on the zombie as a posthuman figure in that it seeks to understand the functions and the usability of the monster specifically as a digital game character through analyzing examples such as Stubbs the Zombie in Rebel Without a Pulse (Wideload Games, 2005). In the end, this article is aimed at investigating the zombie as a queer figure that transgresses several boundaries in games, and ultimately offers us the possibility of transcending the human condition.
\end{abstract}

\section{Keywords}

game, digital game, zombie, monster, queer, queering, player, game character, avatar, figure, symbol, role, self, agency, adversary, enemy, posthumanism, human, nonhuman, transgression, popular culture, horror, Stubbs the Zombie in Rebel Without a Pulse, Dying Light 
This is the final accepted manuscript version. Please cite the official publication:

Sihvonen, Tanja (2019) Queering the Zombie. In Stephen Webley \& Peter Zackariasson (Eds.) The Playful Undead and Video Games: Routledge Advances in Game Studies. London \& New York: Routledge.

\title{
Queering the Zombie
}

\author{
Tanja Sihvonen
}

\section{Understanding the Monster Figure}

In many mainstream digital games, slaying adversaries appears an essential and indisputable game mechanic. Any attempt at making the player to critically reflect on this mechanic and pause to ponder the situation from the enemy's point of view can be seen as norm-breaking. In some games, however, the player is not invited to play the part of a hero that rights the wrongs and saves the day. Instead, in some horror games it may even be possible to assume the role of a monster, the destructible antagonist, which further complicates the already convoluted relationship between the player and her avatar. As monsters indulge us in transgressions normally forbidden to us, and thus reconfirm virtues of the normal (Ingebretsen 1998), the players of monster characters can be regarded to transgress from the general norms of digital gameplay on multiple levels. Harnessing the power of a monster figure as the basis of a player character may profoundly change game mechanics and the formula of horror. This chapter is focused on examining this change: it seeks to understand the transgressive potentials and possibilities of playing the monster.

Even though the cultural characteristics and functions of various kinds of monsters are similar, there are also a number of important differences between them. In this chapter, I am interested in finding out how zombies, in particular, work as game characters. Zombies are far away from the elegance and aristocracy of other monsters, especially vampires: it is easy to 
This is the final accepted manuscript version. Please cite the official publication:

Sihvonen, Tanja (2019) Queering the Zombie. In Stephen Webley \& Peter Zackariasson (Eds.) The Playful Undead and Video Games: Routledge Advances in Game Studies. London \& New York: Routledge.

envisage vampire as the player's avatar in digital role-playing games (even if the potential of vampire avatars has not yet been fully explored in digital games compared to tabletop or live action role-playing games), but it is nearly impossible to fathom similar individual agency to a zombie character. To put it bluntly, it seems that in the world of games, playing (as) the zombie is actively discouraged. This general observation is linked to the aim of my chapter: I want to find out, first, how the traditional figure of a zombie works as a monster in popular culture, and second, how digital games open up new possibilities for the zombie to exist and to do its (dirty) work. At the bottom of this lies the observation that zombies - like vampires, werewolves, witches, and other monsters - are all created by (and from) humans, and thus serve specific cultural and sociopolitical purposes. The zombie has symbolic power, which in the age of digital games manifests itself in new ways and guides players to re-question the limits of their agency and independence in the gameworlds they choose to inhabit (Kee 2017).

This de-stabilizing of the zombie as the monster figure in games is investigated through a process which I call queering. I am using the term 'queer' to denaturalize the object of study, so to speak, to signify the continual unhinging of certainties and the systematic disturbing of the familiar by the processes of undoing normative entanglements and fashioning alternative imaginaries (Giffney \& Hird 2008). Queer is "anything which actively disrupts normativity, transgresses the boundaries of propriety, and interferes with the status quo in closed social and sexual systems" (Bernhardt-House 2008, 159). Practically speaking, through queering the zombie figure I want to find out whether any kind of individual agency is possible for zombies in digital games, or, on what terms zombies can function as player characters (see also Habel \& Kooyman 2014; Kee 2017), which associates my aim with the development of 
This is the final accepted manuscript version. Please cite the official publication:

Sihvonen, Tanja (2019) Queering the Zombie. In Stephen Webley \& Peter Zackariasson (Eds.) The Playful Undead and Video Games: Routledge Advances in Game Studies. London \& New York: Routledge.

posthumanist theory. For the purposes of this article, I define posthumanism loosely as an analytic stance that grants agency to nonhuman entities and critically approaches the differentiation between human and nonhuman actors (see Braidotti 2013). In addition to me as an outsider evaluating and trying to understand the figure of the zombie through etic theory, I will develop and utilize posthumanist thinking and emic perspectives, through which it is possible to look at the zombie from its own viewpoint and native self-understanding (see Bernhardt-House 2008).

This analysis differs from earlier scholarship on the zombie as posthuman (e.g. Christie \& Lauro 2011) in that it seeks to understand the functions and the usability of this monster figure specifically as a digital game character. In order to do this, I first need to unpack the cultural dynamics particular to zombies as classic monsters, and then move on to analyzing the role and position of the zombie in the context of games. This article is theoretically oriented, although I will make use of numerous examples - the third-person actionadventure/horror game Stubbs the Zombie in Rebel Without a Pulse (Wideload Games, 2005) in particular - through which I intend to illustrate my points. My text will tap into the conflict between humanist and posthumanist ideas (e.g. Giffney 2008), and I aim to say something about the ethics of treating the 'Other' through analyzing representations of the zombie figure (see Backe \& Aarseth 2013), as well as letting the Other take care of its own business. My quest of queering the zombie in digital games resembles Kee's analysis of the "zombie self" in search of valuation and "as worthy of life and everything that entails" $(2017,26)$. In the end, I want to develop a way to analyze zombie as a queer figure that transgresses several boundaries in games, and ultimately offers us the possibility of transcending the human condition. 
This is the final accepted manuscript version. Please cite the official publication:

Sihvonen, Tanja (2019) Queering the Zombie. In Stephen Webley \& Peter Zackariasson (Eds.) The Playful Undead and Video Games: Routledge Advances in Game Studies. London \& New York: Routledge.

\section{Dynamics and Motivations of Zombies}

In order to understand how the zombie figure might be queered in digital games, I start with examining the internal dynamics and motivations of zombies as agents in mediasphere and especially in the gameworlds we inhabit. Although monsters have existed among us since ancient times, through digital media and technology, they come into our homes and into our lives in unexpected ways that merit further investigation. In addition to their rich cinematic history, zombies are prevalent in digital games; in their fast, slow, mutated, and virusinfected forms they beg the player to annihilate them in new and inventive ways. If the classic zombie is not where the players would expect it to be, they will complain - as the executive producer Hiroyuki Kobayashi explained when being asked why Resident Evil 6 (Capcom, 2012) brought the old enemy back (see Spencer 2012). According to popular interpretation, the lasting popularity of zombies is based on them being just plain fun to kill (Veloria 2017). But why is popular culture so fascinated with zombies, and which purpose do they serve? Why are contemporary digital games rife with zombies? Is there something specific in the cultural 'composition' of zombies that makes them particularly fitting into our mediated narratives and game mechanics?

Zombie, the walking dead, is a classic monster figure that has been frequently utilized in popular culture since the 1930 s, and although it has transformed from its original form in the Haitian Vodou folklore, its fundamental characteristics have stayed fairly similar throughout decades. Zombies are corpse-like creatures that are turned mindless and mechanical due to outside influence, and their only motivation seems to be preying for food, usually human 
This is the final accepted manuscript version. Please cite the official publication:

Sihvonen, Tanja (2019) Queering the Zombie. In Stephen Webley \& Peter Zackariasson (Eds.) The Playful Undead and Video Games: Routledge Advances in Game Studies. London \& New York: Routledge.

flesh and brains. The zombie has neither free will nor autonomy: it is either a slave or a cannibal whose will has been subsumed by an animalistic urge to eat (Kee 2017). The figure of the zombie represents the most fundamental miracle and/or crime against nature, the transgression of the boundary between life and death. As (moving) corpses are the in-between of human and inhuman, they work against the very human-oriented concepts of gender, sexuality, embodiment, and ethics (see MacCormack 2008). Zombies are thus not only created by humans (or should I say, from humans), but they are also the natural enemy and the antithesis of humans. Beneath the surface, however, the zombie figure reveals a great deal about human anxieties and fears, and we can learn about ourselves and our culture from those who harness the power of monsters to do their social dirty work (Cohen 1996; Platts 2013). This kind of contemplation can be linked to the dark, shadowy locations of horror films and digital gameworlds where culturally marginal and potentially liminal work takes place (Ingebretsen 1998).

In general, the function of the monstrous is to bring about an encounter between the symbolic order and that which threatens its stability (Creed 1993). This dichotomy is mediated by the imaginary (e.g. Krzywinska 2015). Monsters in culture are metaphors, rhetorical figures that are built on the analogy between different semantic fields. It is precisely because they resist capture in the epistemological nets that they remain popular (Cohen 1996). Monsters in literature, media and popular culture are instrumental in that they portray good and evil at work at the same time, stage villainy, develop and anchor plotlines, and simply put, make heroism possible. They also make great figures for spectacle, especially in audiovisual media (Wood \& Schillace 2014). According to Ingebretsen (2001), the rhetoric of monstrosity is a patterned and predictable genre of discourse that follows a certain formula: first, a monster is 
This is the final accepted manuscript version. Please cite the official publication:

Sihvonen, Tanja (2019) Queering the Zombie. In Stephen Webley \& Peter Zackariasson (Eds.) The Playful Undead and Video Games: Routledge Advances in Game Studies. London \& New York: Routledge.

created or discovered, then it is subjected to interpretive prognostication, and finally, the monster is slayed. Monsters are thus mechanisms of stress-release, they indulge us in transgressions normally forbidden to us, and by doing that, they reconfirm "the virtues of the normal for those who, from time to time, need persuading" (Ingebretsen 1998, 25).

So, to answer my questions of why there are zombies and what purpose they serve: The figure of a monster shows us who we are by demonstrating what we shall be if we fail to keep up our necessary social performance - the performance by which we confirm to ourselves and to others that we are human. Zombie stories often most reflect our fear of loss of identity (Collins \& Bond 2011) or loss of control over the self (Kee 2017). At the same time, the monster appears as attractive to us because it is allowed to exhibit behaviours that we deny from ourselves (Mäyrä 2011). The monster, the nonhuman, is therefore an important constituent in the processes of negotiating the boundaries and collective understanding of what it means to be human and to live as a member of a community. The purpose of dealing with and obliterating a monster is to perform specific narrative and social work for the community, such as provide examples of how not to think and act (Ingebretsen 1998). This rhetoric in society functions as a kind of social hygiene that helps keep citizens straight. It is used to justify violence - first, rhetorical, and in the end, physical. Monsters are important for civic health, and their existence has a very specific end goal that stabilizes the status quo of a society: in the end, they always need to die (Ingebretsen 1998).

Eliminating the monster often results in a tighter and more functional community, as we can see in many millennial zombie films and TV series (Collins \& Bond 2011). A strong communal bond is being constituted on the moment of killing the monster. On the outskirts of this community are monsters who refuse to die and continue to be part of it, and part of us; 
This is the final accepted manuscript version. Please cite the official publication:

Sihvonen, Tanja (2019) Queering the Zombie. In Stephen Webley \& Peter Zackariasson (Eds.) The Playful Undead and Video Games: Routledge Advances in Game Studies. London \& New York: Routledge.

they are "our failed selves" (Ingebretsen 1998, 29). From this follows that monsters are objects of both fear and desire, anxiety and fantasy (Cohen 1996) and even more disturbingly - as the human and nonhuman experiential realms are inevitably bound to each other monsters and those who hunt them can be mistaken for one another (Ingebretsen 1998; Ingebretsen 2001). The monster's task is therefore to guard that often-shifting boundary of the human as well as the classificatory 'order of things' (Foucault 2005) and 'limits of knowing' we would occasionally like to challenge (Cohen 1996; Ingebretsen 1998).

What I have described here relates to the analysis of the zombie as a traditional monster, whose job is to serve as a counterpart and object of human action in a dichotomous relationship. The dichotomies of the zombie mark it as a threshold figure, which in addition to straddling the boundary between the living and the dead, also marks the liminal space between past and future (Keetley 2012). The second part of my investigation deals with the context of digital games which opens up new possibilities for the utilization of the zombie's liminality and symbolic power. Digital games, and games in general, differ from earlier media in the sense that their fundamental logic is not only based on representation but simulation, too, as game players can often choose what their game characters look like, how they behave, and what their end goal is. For charged monster figures like the zombie this means that their symbolic power can be harnessed for uses and purposes that have not been experimented with before (Backe \& Aarseth 2013). In order for us to understand how that power may be queered, I first have to take a deeper look into how its history and dynamics are employed in digital games. 
This is the final accepted manuscript version. Please cite the official publication:

Sihvonen, Tanja (2019) Queering the Zombie. In Stephen Webley \& Peter Zackariasson (Eds.) The Playful Undead and Video Games: Routledge Advances in Game Studies. London \& New York: Routledge.

\section{Zombie Gameplay}

Many digital gameworlds are dark places that are especially fit for the innumerable monsters to roam. Games such as the Resident Evil series (Capcom, 1996-2017), Call of Duty: Black Ops (Treyarch, 2010), and Dead Island (Techland, 2011) build upon the maintenance of a fixed and antagonistic dichotomy between humans and zombies that is expressed by the player's avatar killing hordes of mindless adversaries. When the antagonists die and the perpetrator stays alive, the game ends happily. As the purpose of the player character is to stay alive, even if injured, and escape the threat, the zombie horde stays back as abject and interstitial as ever (Habel \& Kooyman 2014). Although the player's individual autonomy and agency is challenged by these liminal monsters, she can rest assured that the game mechanics and the game interface protect her in many ways. However, the distinction between the player character, who is 'alive', and zombies, who are 'dead', upon closer inspection renders their status somewhat confusing.

According to Kirkland (2009), digital games are based on an ontology of horror where all inanimate objects could potentially spring to 'life' and become revived in a way or another. Especially horror games are rife with objects, interactions, and elements that seem to mismatch life-like activity - movement - to inanimate pixels on the screen. Even the player's avatar, the player character, as a fundamentally lifeless object that the player directs and guides can be surrounded by a certain uneasiness concerning the possibility of life. Especially in the third person game genres, the game character functions as a surrogate for the player, a focal point for her sense of embodiment, and constitutes the means by which the gamespace is engaged with. The avatar thus becomes both self and the other, acting as a symbol of life and lifelessness at the same time. The relationship between game characters as well as the 
This is the final accepted manuscript version. Please cite the official publication:

Sihvonen, Tanja (2019) Queering the Zombie. In Stephen Webley \& Peter Zackariasson (Eds.) The Playful Undead and Video Games: Routledge Advances in Game Studies. London \& New York: Routledge.

one between player and avatar is ambiguous and ambivalent, at best, and often evoking feelings of anxiety (Waggoner 2009). Therefore Kirkland $(2009,3)$ suggests that "the zombie may be a metaphor for the process of videogame engagement, representing the avatar without player, the computer-controlled figure, without the human soul to make it truly alive", evoking notions of the uncanny, or the Freudian (1919) Unheimlich.

Even if the relationship between player and avatar is always convoluted, the possibilities for a zombie to become an avatar are very limited. As an established monster figure, the zombie acts as a mirror in which the spectator-player can cast a look and take note of all the ways she differs from it. Although zombies are 'alive', they seem to be living an entirely different digital life than the player's avatar. Although moving, zombie bodies do not possess any autonomy or individuality, and the player can easily distinguish between her own agency and zombies' activities in the gameworld (Habel \& Kooyman 2014). It seems that our games are structured on the principle of the player agency being an essential characteristic of the experiential aspects of games (Perron 2009), and since automatic, algorithmic entities cannot have experience, they also lack agency (Kee 2017). However, on a closer look, this distinction is not clear-cut. As I have argued, on the level of the cultural subconscious, these categories are fundamentally not separate - they overlap in the same way that monsters and their hunters in earlier folklore were mistaken for one another (Ingebretsen 1998).

How do games negotiate the possibilities of human-zombie transformation in light of the uncanny notions that they evoke? It seems that many games are at the same time interested in exploring these possibilities and wary of exploring the full (scary) potential of posthuman agency. Some games treat the zombie as part of the game mechanic, by for instance letting the player control hordes of zombies in particular game modes. For example, in Planescape: 
This is the final accepted manuscript version. Please cite the official publication:

Sihvonen, Tanja (2019) Queering the Zombie. In Stephen Webley \& Peter Zackariasson (Eds.) The Playful Undead and Video Games: Routledge Advances in Game Studies. London \& New York: Routledge.

Torment (Black Isle Studios, 1999) the player can command zombie workers at will. Joining the zombie team in multiplayer mode is an option in games such as Left 4 Dead (Turtle Rock Studios, 2008), Left 4 Dead II (Valve, 2009), and Undead Overlord (JumpCore Productions, 2014), whereas strategically commanding groups of zombies - becoming a "zombie master" (Kee 2017, 135-136) - is possible in games like Zombie Tycoon (Frima Studio, 2009) and Zombie Wranglers (Frozen Codebase, 2009). Another way to let the player experience the gameworld as a zombie is to briefly allow her to act as one, either in the time of death, or birth/resurrection. For example, in Blood (Monolith Productions, 1997) the player starts the game by rising from the grave as an undead character. Also games such as Evil Dead: Regeneration (Cranky Pants Games, 2005) and Zombie panic! Source (a Half Life 2 mod, 2007) feature various kinds of options for lightly zombified play. The player can, for instance, be half deadite, search for brains to eat, and choose between joining either the human or the zombie army that battle against each other.

Lightly zombified play is also possible in the run-and-gun shooters Metal Slug 3 (SNK, 2000) and Metal Slug 4 (SNK, 2002), in which there are missions with specific paths where the player character turns into a zombie for a moment after being hit by enemy zombies. These zombie transformations are written in the game narrative as momentary periods, and during these the avatar gains control of specific abilities and weaponry in addition to the normal arsenal. In Metal Slug 3, the zombified player character can only move slowly and cannot crouch or jump, but he can make use of a powerful vomit attack that obliterates everything around him, while being immune to attacks from enemies (e.g. Retrovaniacs 2017).

In the Resident Evil series of survival horror/action-adventure games, the player can turn into a zombie in multiplayer mode at least in Resident Evil: Outbreak and its standalone 
This is the final accepted manuscript version. Please cite the official publication:

Sihvonen, Tanja (2019) Queering the Zombie. In Stephen Webley \& Peter Zackariasson (Eds.) The Playful Undead and Video Games: Routledge Advances in Game Studies. London \& New York: Routledge.

expansion Resident Evil Outbreak: File \#2, as well as in Resident Evil 6 (2012). In Resident Evil 6, the player can choose to join an ongoing multiplayer match as an 'enemy' for another player in the middle of a story mode they are hosting. These specific game modes include zombified character options such as an eagle and a hound, in addition to variously shaped human-resembling zombies, and the player's goal is to kill the host before they leave the area. The system is structured so that the player character has the same health, speed, and stamina as a normal NPC of the same type of creature she is playing as. Despite the impressive looks and varied controls that the avatar possesses in these occasions, the zombie still assumes a position of an easily killable and disposable monster in this mode (e.g. quackalakes 2012a, 2012b, 2012c). Zombification in these games may change the player's targets, but it does not alter the logic of the game: the gameplay still consists of destroying the adversaries, and the zombies still remain 'bad' (Kee 2017).

If the distinction between human and zombie characteristics and action becomes blurred it eventually starts to be challenging to keep the human and nonhuman realms separate. As Collins and Bond (2011) note, it is increasingly difficult to differentiate the human from the zombie if, for instance, individuality has been erased from the equation. Zombie is posthuman in the literal meaning of the term - it both has the characteristics and looks of a human being while not being quite human anymore. Zombies are 'things', but at the same time they are just people who have somehow lost their status as fully human (Kee 2017). When a notion of their similarity has been evoked, zombie as a foe starts to look even more frightening and titillating (cf. Castillo 2014), making its annihilation specifically pleasurable and rewarding for many players. Zombie makes the perfect enemy and target for action in shooters, horror games, action-adventure games, and even platform puzzles, and it is no 
This is the final accepted manuscript version. Please cite the official publication:

Sihvonen, Tanja (2019) Queering the Zombie. In Stephen Webley \& Peter Zackariasson (Eds.) The Playful Undead and Video Games: Routledge Advances in Game Studies. London \& New York: Routledge.

wonder that it has retained its place as one of the classic antagonists through decades of gaming history (Krzywinska 2008).

One of the most advanced possibilities of playing as a zombie at the moment can be found in the freely downloadable extra feature for the first-person survival horror game Dying Light (Techland, 2015) called Be a Zombie Mode. It is special content for the game, a competitive multiplayer mode add-on, which lets the player to inhabit the freely roamable world as a zombie, protect their nests, and annihilate human opponents. Even though Dying Light is not a role-playing game, some of its characters' features drive the analysis towards looking into it as such. The zombie player character can use Spiderman-style tendril hookshots to swing across walls and rooftops to swiftly move around. Zombies in the game are extremely sensitive to UV lights, which are in the possession of humans, and casting these lights on them lowers their stamina and makes them slower to flee. However, if the stealth tactic of the zombie is successful, he can sneak up on the human opponent and kill them instantly with a grab (Be a Zombie Mode 2015).

Nevertheless, in Dying Light the zombie character is always the only player-controlled zombie in the game, as the other participants play as humans; in addition, there are NPCs that are always zombies. Assuming the role of a zombie even in Dying Light resembles more of a transitory tryout than a proper role-playing experience. Being a zombie in the game involves communication with peers through howling, protecting nests, killing humans, as well as trying to hide away from blinding UV lights. As far as the zombie's senses are concerned, he sees everything in black and white (Stapleton \& Reparaz 2015). All of these features associate the zombie to animals - in fact, many characteristics in the composition of the zombie as a cultural figure point towards regarding it as bestial, instinctive, predatory, and 
This is the final accepted manuscript version. Please cite the official publication:

Sihvonen, Tanja (2019) Queering the Zombie. In Stephen Webley \& Peter Zackariasson (Eds.) The Playful Undead and Video Games: Routledge Advances in Game Studies. London \& New York: Routledge.

brutal. In conclusion, the zombie character, albeit being piloted by a human player, is in many of these games still a monster whose role is to be the foe of the human player subject. Most of the games that feature options for zombified play are not really harnessing the full potential of the uncanny monster.

\section{Towards Zombie Agency in Games}

As I have demonstrated so far, the cultural place of zombie as the monster figure is tied to being the antagonist and to providing a suitable backdrop for heroic human agency. The zombie is often just a mechanical plot device: "its loss of agency parallels its loss of the ability to feel (as a human) and its loss of value (as a human)" (Kee 2017, 8). However, this juxtaposition is far from clear. Media that tells us about monsters often complicate the dichotomy between 'us' versus 'them', and in so doing, these cultural narratives effectively problematize our definitions of what it means to be human (Carr 2009). Many monster stories are actually about humans that behave like monsters, and get punished respectively, and likewise many powerful narratives explore the potential remnants of humanity in undead creatures - a mainstream popular culture tradition that began when Mary Shelley's Frankenstein; or, The Modern Prometheus was published in 1818. The eruption of these kinds of dichotomies leads us to the current conflict between humanism and posthumanism.

The erosion of the binary between the self and the Other that I have discussed in relation to games reflects the posthumanist assertion that the definition of human is always contextual, open for interpretation, and contingent upon the current reorganization of knowledge. The posthumanist argument resonates especially with Michel Foucault's seminal work (e.g. 2005) 
This is the final accepted manuscript version. Please cite the official publication:

Sihvonen, Tanja (2019) Queering the Zombie. In Stephen Webley \& Peter Zackariasson (Eds.) The Playful Undead and Video Games: Routledge Advances in Game Studies. London \& New York: Routledge.

that highlights the conception of what it means to be human as historically structured processes which depend on epistemologies, language, and patterns of thought that rearrange themselves according to various spatiotemporal coordinates. Beginning in the latter part of the $20^{\text {th }}$ century, the exploration of the extent to which technology defines or comprises humanity, has also gained considerable momentum (Haraway 1991). This means that the concept of 'human' has been rearticulated, contested, and even replaced many times over (Grusin 2015).

Bennett (2015) suggests that the big project associated with the posthuman turn might be to find new ways of allowing the nonhumans to exist in the human world on their own terms. As I have outlined in this text, it is not only the category of human that is prone to the kinds of monstrous transgressions that zombie games offer, but the zombie as a symbolic figure makes an entrance onto the terrain of the player character, thus potentially gaining experientiality, agency, and individuality in the process. Even though the narrative frame of the antagonistic zombie figure in the cinema, television, comic books, and other works of popular culture is solidified to the point that it may be impossible for us to imagine a positive and autonomous zombie agency (Platts 2013), games have the possibility to be more experimental in this regard. There are few technical obstacles to allow zombies to have full agency in games. However, as digital game development is painstaking and expensive, the anticipated commercial and sociopolitical potential of zombies as player characters may not be up to par. Culturally speaking, however, increasing diversity among game characters and offering players the potential to experience the world through diverging viewpoints - i.e. queering the characters - are goals worth pursuing. These kinds of options are most fruitfully explorable in role-playing games (Sihvonen \& Stenros 2018). 
This is the final accepted manuscript version. Please cite the official publication:

Sihvonen, Tanja (2019) Queering the Zombie. In Stephen Webley \& Peter Zackariasson (Eds.) The Playful Undead and Video Games: Routledge Advances in Game Studies. London \& New York: Routledge.

In the third-person game Stubbs the Zombie in Rebel Without a Pulse (Wideload Games, 2005), the main player character is a wisecracking zombie whose primary goal is to slay humans and devour their brains. Eating human brains not only gives the character health points but also converts the victims into zombies and ally fighters. In addition to eating brains and zombifying humans, the gameplay consists of piloting various kinds of vehicles and possessing enemies via detached body parts (Seropian 2006). The zombie state of the player character prevents him from using conventional arsenal, so instead he wields weaponry based on his own decaying body: he can use his guts as grenades, send his detached head bowling into his enemies, stun his adversaries with flatulence, and possess them through his body parts to gain access to their weapons. He "can exploit both living and 'dead' technologies to his advantage" (Kee 2017, 138). Furthermore, Stubbs does not only destroy his enemies; from a zombie perspective, he also gives them new life - as zombies. He can then herd the other zombies by whistling, and his followers can also kill humans and eat their brains, thus turning more humans into zombies. Set in the retrofuturistic, fictional city of Punchbowl, US, the game also features a backstory about Stubbs' family history and romantic relationship.

In the game, the (post)human individuality of Stubbs is therefore evoked in a number of ways: in spite of being a zombie, he can communicate, express emotions, and belong to a community. Stubbs as the player character can move about and make decisions according to his own will. He can be innovative in his actions by inventing new weapons, for instance, and even act as a political agent by giving a speech to gathered zombies while standing before an American flag. He has geographical coordinates and a time frame to his personal history. $\mathrm{He}$ is an individual with whom the player is expected to identify and whose problems she is supposed to understand. 
This is the final accepted manuscript version. Please cite the official publication:

Sihvonen, Tanja (2019) Queering the Zombie. In Stephen Webley \& Peter Zackariasson (Eds.) The Playful Undead and Video Games: Routledge Advances in Game Studies. London \& New York: Routledge.

Stubbs the Zombie is an example of an action game that lets the zombie play the main part, but despite the horror thematic still largely relies on the comic effect that results from his actions. Comedy can be interpreted as an attempt to alleviate the disturbing affects that zombie agency brings along, and Stubbs the Zombie is hardly the only zombie game that uses humor in this way. Also serious zombie games, such as Dying Light, occasionally resort to comic relief, for instance by depicting dancing zombies or making a reference to the popular casual game Plants vs. Zombies (PopCap Games, 2009) via a playable minigame within the survival horror gamespace. The use of humor can be interpreted to suggest that there is a new kind of fear that these games evoke: the blurring of boundaries between humans and nonhumans - or civilization and monstrosity. The use of zombified humans as well as humanized zombies as player characters challenges us to reconsider both the humanity of others and the inhumanity of ourselves.

Stubbs is indeed re-humanized in the course of the game: he is shown to have a family and a romantic interest, and a personal history that unfolds as the gameplay progresses. He teaches us, then, that it is the relationships and connections with others that help us pass as human. His character no longer works against the fundamental aspects of gender, sexuality, embodiment, and ethics (see MacCormack 2008). In this respect, Stubbs can be considered a queered zombie, one that has obtained the status of an independent, autonomous, and feeling agent through digital gameplay, without losing his zombieism. Even if Stubbs the Zombie, according to some critics, resulted in mediocre gameplay (Price 2005), the game remains an interesting experiment at innovating the horror genre by redefining zombie as the main player character and the center of attention. The game's development was possible since it was 
This is the final accepted manuscript version. Please cite the official publication:

Sihvonen, Tanja (2019) Queering the Zombie. In Stephen Webley \& Peter Zackariasson (Eds.) The Playful Undead and Video Games: Routledge Advances in Game Studies. London \& New York: Routledge.

made by an independent game studio that had a fresh approach to the horror genre and decidedly wanted to shake the conventions of zombie games (Seropian 2006).

In the end, the playable zombie can be regarded as a 'hybrid', queer figure that transgresses several boundaries in addition to negotiating the line between life and death. Through inviting us to become the zombie, they offer us the possibility of transcending the human condition. The zombie is a monster that the orderly logic of society is unable to ever fully explain, classify or assimilate. The queer zombie Stubbs can be interpreted as a positive figure, one that provides us with an example of experimental strategies and adaptive advantages for survival. In order to play Stubbs the Zombie successfully, the player must learn to think and act like a zombie - to take advantage of decomposition and different methods of communication, and to run towards human enemies, not away from them, in order to zombify them. This approach resembles Deuze's (2013) provoking thesis about (media) zombification that characterizes our lives and provides us with opportunities "for more or less new types of social engagement" (Deuze 2013, 2). If zombieism is accepted as an alternative form of humanity that acknowledges and celebrates its animalistic side, it becomes an image of queerness which potentially proves very empowering for those willing to accept it (see Bernhardt-House 2008). Letting the queer posthuman to act as our ally - or even our self - in games makes it possible for transgression to happen through play, and this has the power to both subvert existing meanings and help us make new ones every time we play.

\section{References}


This is the final accepted manuscript version. Please cite the official publication:

Sihvonen, Tanja (2019) Queering the Zombie. In Stephen Webley \& Peter Zackariasson (Eds.) The Playful Undead and Video Games: Routledge Advances in Game Studies. London \& New York: Routledge.

Backe, Hans-Joachim \& Espen Aarseth (2013) Ludic Zombies: An Examination of Zombieism in Games. Proceedings of DiGRA 2013: DeFragging Game Studies.

http://homes.lmc.gatech.edu/ cpearce3/DiGRA13/papers/paper 405.pdf

Be a Zombie Mode (2015) Dying Light Wiki, 1 February 2015.

http://www.ign.com/wikis/dying-light/Be a Zombie_Mode

Bennett, Jane (2015) Systems and Things On Vital Materialism and Object-Oriented Philosophy. - Grusin, Richard (Ed.) The Nonhuman Turn. Minneapolis: University of Minnesota Press, 223-239.

Bernhardt-House, Phillip A. (2008) The Werewolf as Queer, the Queer as Werewolf, and Queer Werewolves. - Giffney, Noreen \& Myra J. Hird (Eds.) Queering the Non/Human. Aldershot: Ashgate, 159-183.

Braidotti, Rosi (2013) The Posthuman. Cambridge \& Malden, MA: Polity Press.

Carr, Diane (2009) Textual Analysis, Digital Games, Zombies. Proceedings of the 2009 DiGRA Conference: Breaking New Ground: Innovation in Games, Play, Practice and Theory. http://www.digra.org/dl/display_html?chid=09287.24171.pdf

Castillo, David (2014) Monsters for the Age of the Post-Human. - Adriana Gordillo \& Nicholas Spadaccini (Eds.) Writing Monsters: Essays on Iberian and Latin American Cultures. Hispanic Issues On Line 15, 161-178.

Christie, Deborah \& Sarah Juliet Lauro (Eds.) (2011) Better Off Dead: The Evolution of the Zombie as Post-Human. New York: Fordham University. 
This is the final accepted manuscript version. Please cite the official publication:

Sihvonen, Tanja (2019) Queering the Zombie. In Stephen Webley \& Peter Zackariasson (Eds.) The Playful Undead and Video Games: Routledge Advances in Game Studies. London \& New York: Routledge.

Cohen, Jeffrey Jerome (1996) Monster Culture (Seven Theses). - Jeffrey Jerome Cohen (Ed.) Monster Theory. Reading Culture. Minneapolis \& London: University of Minneapolis Press, $3-25$.

Collins, Margo \& Elson Bond (2011) “Off the page and into your brains!”: New Millennium Zombies and the Scourge of Hopeful Apocalypses. - Deborah Christie \& Sarah Juliet Lauro (Eds.) Better Off Dead: The Evolution of Zombie as Post-Human. New York: Fordham University Press, 187-204.

Creed, Barbara (1993) The Monstrous-feminine: Film, Feminism, Psychoanalysis. London: Routledge.

Deuze, Mark (2013) Living as a Zombie in Media (is the Only Way to Survive). MATRIZes 7(2), 1-19. DOI: http://dx.doi.org/10.11606/issn.1982-8160.v7i2p113-129

Foucault, Michel (2005) The Order of Things: An Archaeology of the Human Sciences. London \& New York: Routledge.

Freud, Sigmund (1919) The 'Uncanny'. - The Standard Edition of the Complete Psychological Works of Sigmund Freud. Transl. James Strachey, vol. XVII. London: Hogarth Press \& the Institute of Psycho-Analysis, 219-252. https://uncanny.la.utexas.edu/wpcontent/uploads/2016/04/freud-uncanny 001.pdf

Giffney, Noreen (2008) Queer Apocal(o)ptic/ism: The Death Drive and the Human. Giffney, Noreen \& Myra J. Hird (Eds.) Queering the Non/Human. Aldershot: Ashgate, 5578. 
This is the final accepted manuscript version. Please cite the official publication:

Sihvonen, Tanja (2019) Queering the Zombie. In Stephen Webley \& Peter Zackariasson (Eds.) The Playful Undead and Video Games: Routledge Advances in Game Studies. London \& New York: Routledge.

Giffney, Noreen \& Myra J. Hird (2008) Introduction: Queering the Non/Human. - Giffney, Noreen \& Myra J. Hird (Eds.) Queering the Non/Human. Aldershot: Ashgate, 1-16.

Grusin, Richard (2015) (Ed.) The Nonhuman Turn. Minneapolis: University of Minnesota Press.

Habel, Chad \& Ben Kooyman (2014) Agency Mechanics: Gameplay Design in Survival Horror Video Games. Digital Creativity 25(1), 1-14. DOI: 10.1080/14626268.2013.776971 Haraway, Donna (1991) [1984] A Cyborg Manifesto: Science, Technology, and SocialistFeminism in the Late Twentieth Century. - Simians, Cyborgs and Women: The Reinvention of Nature. London: Free Association Press.

Ingebretsen, Edward J. (1998) Monster-making: A Politics of Persuasion. The Journal of American Culture 21(2), 25-34. DOI: 10.1111/j.1542-734X.1998.00025.x

Ingebretsen, Edward J. (2001) At Stake: Monsters and the Rhetoric of Fear in Public Culture. Chicago: University of Chicago Press.

Kee, Chera (2017) Not Your Average Zombie: Rehumanizing the Undead from Voodoo to Zombie Walks. Austin: University of Texas Press.

Keetley, Dawn (2012) Zombie Evolution: Stephen King's Cell, George Romero's Diary of the Dead, and the Future of the Human. Americana 11(2), 1-

9. http://www.americanpopularculture.com/journal/articles/fall_2012/keetley.htm 
This is the final accepted manuscript version. Please cite the official publication:

Sihvonen, Tanja (2019) Queering the Zombie. In Stephen Webley \& Peter Zackariasson (Eds.) The Playful Undead and Video Games: Routledge Advances in Game Studies. London \& New York: Routledge.

Kirkland, Ewan (2009) Horror Videogames and the Uncanny. Proceedings of DiGRA 2009:

Breaking New Ground: Innovation in Games, Practice and Theory. DiGRA Digital Library. http://www.digra.org/digital-library/publications/horror-videogames-and-the-uncanny/

Krzywinska, Tanya (2008) Zombies in Gamespace: Form, Context, and Meaning in Zombiebased Videogames. - McIntosh, Shawn \& Marc Leverette (Eds.) Zombie Culture. Autopsies of the Living Dead. Lanham: Scarecrow Press, 153-168.

Krzywinska, Tanya (2015) The Gamification of Gothic Coordinates in Videogames.

Revenant 1(1), 54-78. http:/www.revenantjournal.com/wp-content/uploads/2015/11/TanyaKrzywinska-The-Gamification-of-Gothic-Coordinates-in-Videogames.pdf

MacCormack, Patricia (2008) Necrosexuality. - Giffney, Noreen \& Myra J. Hird (Eds.)

Queering the Non/Human. Aldershot: Ashgate, 339-362.

Mäyrä, Frans (2011) From the Demonic Tradition to Art-Evil in Digital Games: Monstrous Pleasures in Lord of the Rings Online. - Krzywinska, Tanya, Esther MacCallum-Stewart \& Justin Parsler (Eds.) Ringbearers: The Lord of the Rings Online as Intertextual Narrative. Manchester: Manchester University Press, 111-135.

Perron, Bernard (2009) The Survival Horror: The Extended Body Genre. In B. Perron (Ed.) Horror Video Games. Jefferson, NC: McFarland, 121-143.

Platts, Todd K. (2013) Locating Zombies in the Sociology of Popular Culture. Sociology Compass 7, 547-560. DOI: 10.1111/soc4.12053

Price, James (2005) Stubbs the Zombie in Rebel Without A Pulse. Eurogamer.net 23 December 2005. http://www.eurogamer.net/articles/r_stubbszombie X 
This is the final accepted manuscript version. Please cite the official publication:

Sihvonen, Tanja (2019) Queering the Zombie. In Stephen Webley \& Peter Zackariasson (Eds.) The Playful Undead and Video Games: Routledge Advances in Game Studies. London \& New York: Routledge.

quackalakes (2012a) Resident Evil 6 - Agent Hunt Mode (Creature Mode) - Part 1 - I'm a dog! [HD]. YouTube 5 October 2012. https://youtu.be/hxN25HeQVQw

quackalakes (2012b) Resident Evil 6 - Agent Hunt Mode (Creature Mode) - Part 2 - Fun, Derpy Zombies! YAY! [HD]. YouTube 14 October 2012. https://youtu.be/iY dJCeEXyU quackalakes (2012c) Resident Evil 6 - Agent Hunt Mode (Creature Mode) - Part 3 - Eagles and Snow Mobiles! [HD]. YouTube 19 October 2012. https://youtu.be/f6U5VaEpfe4

Retrovaniacs, Jeremy P. (2017) METAL SLUG 3 - Zombie Transformation. YouTube 23 January 2017. https://youtu.be/y4tc4dQLxiA

Seropian, Alexander (2006) Postmortem: Wideload Games' Stubbs the Zombie. Gamasutra 11 August 2006.

http://www.gamasutra.com/view/feature/130263/postmortem_wideload_games_stubbs_.php Sihvonen, Tanja \& Jaakko Stenros (2018) Cues for Queer Play: Carving a Possibility Space for LGBTQ Role-Play" - Taylor, Nick, Meghan Blythe Adams \& Todd Harper (Eds.) Games \& Gender, vol. 3. London: Palgrave Macmillan (forthcoming).

Spencer (2012) Why Capcom Brought Zombies Back For Resident Evil 6. Siliconera 26 July 2012. http://www.siliconera.com/2012/07/26/why-capcom-brought-zombies-back-for$\underline{\text { resident-evil-6/ }}$

Stapleton, Dan \& Mikel Reparaz (2015) Dying Light - Review-in-Progress Commentary, Day 5. IGN 30 January 2015. http://www.ign.com/videos/2015/01/31/dying-light-review-inprogress-commentary-day-5 
This is the final accepted manuscript version. Please cite the official publication:

Sihvonen, Tanja (2019) Queering the Zombie. In Stephen Webley \& Peter Zackariasson (Eds.) The Playful Undead and Video Games: Routledge Advances in Game Studies. London \& New York: Routledge.

Veloria, Lorenzo (2017) The 13 best zombie games you can play right now. GamesRadar 26 January 2017. http://www.gamesradar.com/best-zombie-games/

Waggoner, Zach (2009) My Avatar, My Self: Identity in Video Role-playing Games.

Jefferson, NC \& London: McFarland.

Wood, Andrea \& Brandy Schillace (2014) (Eds.) Unnatural Reproductions and Monstrosity: the Birth of the Monster in Literature, Film, and Media. Amherst: Cambria. 